\title{
Cascade screening for familial hypercholesterolemia-identification of the C308Y mutation in multiple family members and relatives for the first time in mainland China
}

Weirong Jin ${ }^{1 \dagger}$, Qiuwang Zhang ${ }^{2 \dagger}$, Bei Wang ${ }^{3}$, Lili Pan ${ }^{3}$, Hongyou Qin ${ }^{1}$, Daying Yang ${ }^{3}$, Xiangqun Zhou ${ }^{3}$, Yongcai Du ${ }^{3}$, Ling Lin $^{3^{*}}$ (D) and Michael J. Kutryk ${ }^{2}$

\begin{abstract}
Background: Familial hypercholesterolemia (FH), an autosomal dominant genetic disorder, is underdiagnosed and undertreated. The majority of FH cases are caused by low density lipoprotein receptor ( $L D L-R)$ gene mutations. The C308Y mutation in LDL-R results in approximately $70 \%$ loss of LDL-R activity, leading to the elevation of low density lipoprotein-cholesterol (LDL-C) and an increased risk of premature coronary heart disease (CHD). The aim of this study was to identify FH cases by cascade screening in family members and relatives of a 37-year old male with premature CHD and hypercholesterolemia.

Methods: Clinical exam, blood lipid profiling and genomic DNA sequencing of all exons of $L D L-R$ were performed for the proband and his 14 family members and relatives. FH diagnosis was carried out using the Dutch Lipid Clinic Network (DLCN) criteria.

Results: Lipid profiling showed that 9 individuals, including the proband, had hypercholesterolemia. All these 9 subjects had a G > A substitution at nucleotide 986 in exon 7 resulting in the C308Y mutation as determined by DNA sequencing, and all those carrying the mutation were diagnosed as having definite FH under the DLCN criteria. However, most (7/9) did not have suggestive clinical manifestations of CHD.

Conclusions: The C308Y mutation was discovered in multiple family members and relatives for the first time in mainland China. Cascade screening is key for the confirmatory diagnosis of FH. Our hypothesis that the C308Y is a common variant in the population of Southern China origin warrants further validation by screening for the C308Y mutation in a large population.
\end{abstract}

Keywords: Familial hypercholesterolemia, Cascade screening, C308Y mutation, Low density lipoprotein-cholesterol, Low density lipoprotein receptor, DNA sequencing

\footnotetext{
* Correspondence: linling0606@163.com

+Weirong Jin and Qiuwang Zhang contributed equally to this work

${ }^{3}$ Department of Cardiology, the Third People's Hospital of Hainan Province,

1154 Jiefang Road, Sanya 572000, Hainan Province, China

Full list of author information is available at the end of the article
}

(c) The Author(s). 2019 Open Access This article is distributed under the terms of the Creative Commons Attribution 4.0 International License (http://creativecommons.org/licenses/by/4.0/), which permits unrestricted use, distribution, and reproduction in any medium, provided you give appropriate credit to the original author(s) and the source, provide a link to the Creative Commons license, and indicate if changes were made. The Creative Commons Public Domain Dedication waiver (http://creativecommons.org/publicdomain/zero/1.0/) applies to the data made available in this article, unless otherwise stated. 


\section{Background}

Familial hypercholesterolemia (FH) is an autosomal dominant genetic disorder characterized by elevated levels of low density lipoprotein-cholesterol (LDL-C), tendon xanthomas and an increased risk of premature coronary heart disease (CHD) [1]. It is caused by mutations of genes encoding proteins that are responsible for the metabolic clearance of LDL-C. To date, several genes whose mutations linked to $\mathrm{FH}$ have been identified, which include the low density lipoprotein receptor $(L D L-R)$ gene, the apolipoprotein B gene, the proprotein convertase subtilisin/kexin type 9 gene and the LDL receptor adapter protein 1 gene [2]. Most cases (60-80\%) of $\mathrm{FH}$ are caused by mutations in the $L D L-R$ gene [3].

Homozygous $L D L-R$ mutations are rare (1/1 million) [4], but the prevalence of heterozygous $\mathrm{FH}$ is high. A recent meta-analysis of 19 studies covering almost 2.5 million individuals has revealed that the prevalence of heterozygous $\mathrm{FH}$ is $1 / 250$ in general population [5], which doubles a previous estimation of 1/500 [4]. Early diagnosis of $\mathrm{FH}$ is critical for the initiation of effective pharmacological treatment that can lower LDL-C concentrations and reduce the risk of CHD [6].

The $L D L-R$ is a $\sim 45 \mathrm{~kb}$ gene containing 18 exons [7]. Although previous data suggest that the majority of $L D L$ $R$ mutations occur in exons 3 and 4, the current understanding is that mutations causing $\mathrm{FH}$ are distributed throughout the entire gene including promotor, intronic and 3 '-untranslated regions [8]. The updated $L D L-R$ database of University College London (now the Leiden Open Source Variation Database, LOVD) has documented a total of $1959 L D L-R$ variants (https://databases.lovd.nl/ shared/genes/LDLR). Nevertheless, the geographical- or population-specific fingerprints of $L D L-R$ mutations have been noted [9-14]. Therefore, identification of predominant mutations in a certain region or population could direct strategies for molecular detecting. For example, when a small number of mutations predominate, molecular tests can be designed to identify these specific variant alleles, making testing more cost-effective and time saving.

There is a strong consensus on the facts that a diagnosis of FH can be made on the basis of clinical criteria (elevated LDL-C levels, clinical history of premature cardiovascular disease, family history of $\mathrm{FH}$ and physical examination findings such as tendon xanthomas) and/or DNA testing; and that when a pathogenic $\mathrm{FH}$ mutation is identified a definite diagnosis can be made [15-17]. A recent systematic review of guidelines on genetic testing and management of $\mathrm{FH}$ has found that most guidelines recommend the use of DNA testing for cascade screening [18]. DNA testing offers definitive diagnoses, which ensures prompt treatment that can significantly reduce the risk of cardiovascular disease. Additionally, DNA testing is capable of distinguishing heterozygous from homozygous $\mathrm{FH}$, which can direct patient care, as more aggressive therapeutic intervention is required for those with homozygous $\mathrm{FH}$.

A recent systemic review of $L D L-R$ mutations in Chinese population revealed regional clustering of $L D L-R$ mutations, e.g., A606T, D601Y and W462X are the primary mutations found in mainland China while C308Y and $\mathrm{H} 562 \mathrm{Y}$ predominate in Taiwan province and Hong Kong [14]. To date, only one C308Y case has been discovered in mainland China [19]. Here we reported the identification of multiple family members and relatives of a family with the C308Y mutation in Hainan Province, China. Physical examinations, lipid profiling, DNA sequencing and the DLCN criteria were used to investigate the index patient and his 14 family members and relatives.

\section{Methods}

\section{Ethical approval}

This study was approved by the Research Review Committee of the Third People's Hospital of Hainan Province. Written informed consent to participating in the study was obtained from all subjects.

\section{Study subjects}

A 37-year old male (proband) with severe early onset coronary artery disease and his 14 family members and relatives were recruited for this study.

\section{Blood lipid profiling}

Blood lipid testing was routinely performed at the department of clinical laboratory, the Third People's Hospital of Hainan Province.

\section{Measurement of Achilles tendon thickness}

Achilles tendon thickness was measured using a standardized digital radiography method as we described elsewhere [20]. Patients with an Achilles tendon thickness of $\geq 9 \mathrm{~mm}$ was taken as tendon thickening [21].

\section{$L D L-R$ mutation analysis}

Genomic DNA was extracted from 5 to $10 \mathrm{ml}$ peripheral blood using the Blood Genomic DNA Extraction Kit (Tiangen Biotech Co., Ltd., Beijing, China) according to the manufacturer's instructions, and quantified using a ND-1000 spectrophotometer (Thermo Fisher Scientific China Co., Ltd., Shanghai, China). PCR was done to amplify each of 18 exons of $L D L-R$ using $50 \mathrm{ng}$ genomic DNA as template. All primers (Table 1) were designed based on the $L D L-R$ sequence (NCBI Reference Sequence \#: NG_009060.1). PCR was performed as follows: stage $1,95^{\circ} \mathrm{C}$ for $5 \mathrm{~min}$; stage $2,95^{\circ} \mathrm{C}$ for $30 \mathrm{~s}, 55^{\circ} \mathrm{C}$ for $40 \mathrm{~s}$ and $72^{\circ} \mathrm{C}$ for $40 \mathrm{~s}$; and stage 2 was repeated for 35 cycles. Afterwards, the PCR product was purified using 
Table 1 PCR primers for amplifications of all coding exons of $L D L-R$

\begin{tabular}{|c|c|c|c|}
\hline$\overline{\text { Exon }}$ & Forward & Reverse & Product size \\
\hline 1 & 5'-GTGGGAATCAGAGCTTCACG-3' & 5'-GGATGGAGTGATTATTTGTA-3' & $410 \mathrm{bp}$ \\
\hline 2 & 5'-GATTCTGGCGTTGAGAGACC-3' & 5'-AGCGGATCACTTGAGACCAG-3' & $271 \mathrm{bp}$ \\
\hline 3 & 5'-GGTCTTTCCTITGAGTGACAGT-3' & 5'-CCACTITGTAATGCCTCCTGG-3' & $353 \mathrm{bp}$ \\
\hline 4 & 5'-TAGAATGGGCTGGTGTTGGG-3' & 5'-CCAGGGACAGGTGATAGGAC-3' & $496 \mathrm{bp}$ \\
\hline 5 & 5'-GTACAGACACAGGCTGGTCT-3' & 5'-CCCTCTGGCTTCACAAATCA-3' & $372 b p$ \\
\hline 6 & 5'-CACACCTGACCTTCCTCCTT-3' & 5'-TCCCAAAACCCTACAGCACT-3' & $245 \mathrm{bp}$ \\
\hline 7 & 5'-AGTGACCAGTCTGCATCCC-3' & 5'-GGTTGCCATGTCAGGAAGC-3' & $211 \mathrm{bp}$ \\
\hline 8 & 5'-CCAAGCCTCTTTCTCTCTCTTC-3' & 5'-GGGATATGAGTCTGTGCAAAGT-3' & $250 \mathrm{bp}$ \\
\hline 9 & 5'-GCACTCTTGGTTCCATCGAC-3' & 5'-GAGCCCTCATCTCACCTGC-3' & $285 \mathrm{bp}$ \\
\hline 10 & 5'-CAGGTGAGATGAGGGCTCC-3' & 5'-TCCTTCCTGCTCCCTCCAT-3' & $333 \mathrm{bp}$ \\
\hline 11 & 5'-CAGCTATTCTCTGTCCTCCCA-3' & 5'-GTGACAGACCAAGACCTCATC-3' & $306 \mathrm{bp}$ \\
\hline 12 & 5'-CAGCACGTGACCTCTCCTTA-3' & 5'-AGTCTGTGTCTATCCGCCAC-3' & $229 \mathrm{bp}$ \\
\hline 13 & 5'-CCTGTGTCTCATCCCAGTGT-3' & 5'-CAAGGAGGTTTCAAGGTTGGG-3' & $244 \mathrm{bp}$ \\
\hline 14 & 5'-GCTGATGATCTCGTTCCTGC-3' & 5'-GACACAGGACGCAGAAACAA-3' & $232 \mathrm{bp}$ \\
\hline 15 & 5'-CACGTGGCACTCAGAAGAC-3' & 5'-GGACTCCATCTCGTGACCAA-3' & $296 \mathrm{bp}$ \\
\hline 16 & 5'-GGCCTCACTCTTGCTTCTCT-3' & 5'-CCATCTGACCCCTTAGCTGT-3' & $299 \mathrm{bp}$ \\
\hline 17 & 5'-GTITTCACTCCAGCCACGG-3' & 5'-TGGCTTTCTAGAGAGGGTCAC-3' & $258 \mathrm{bp}$ \\
\hline 18 & 5'-TGTTTACCATTTGTTGGCAG-3' & 5'-TTGGTCTTCTCTGTCTTTG-3' & $140 \mathrm{bp}$ \\
\hline
\end{tabular}

the QIAquick PCR Purification Kit (Qiagen China Co., Ltd., Shanghai, China) and sequenced using the Sanger method. DNA sequencing results were analyzed using the software Sequencher 5.0 (Gene Codes Corp., Ann Arbor, MI, USA).

\section{Diagnosis of FH}

The Dutch Lipid Clinic Network (DLCN) criteria were used for the diagnosis of FH. This diagnostic algorithm uses scores created based on the examination results from following 5 areas: family history, clinical history, physical examination, LDL-C levels and molecular genetic testing [17]. According to the score, diagnosis is made as follows: a score of $>8$ points for a 'definite $\mathrm{FH}$; 6 to 8 points for 'probable $\mathrm{FH}^{\prime}$; 3 to 5 points for 'possible FH'; and 0 to 2 points for 'unlikely FH'.

\section{Results}

\section{Study subjects}

The proband presented to our hospital with a two week history of crescendo angina. Coronary angiography showed severe 3-vessel coronary artery disease. Achilles tendon thickness measured $13 \mathrm{~mm}$ bilaterally. The proband's father had a history of CHD, while clinical manifestations suggestive for CHD were not present in other family members and relatives. Of the 5 individuals who consented to measurement of Achilles tendon, 4 had Achilles tendon thickness $\geq 9 \mathrm{~mm}$. The demographics and clinical characteristics of all subjects are described in Table 2.

\section{Blood lipid profiling}

Results of blood lipid testing for all subjects are shown in Table 3. According to the diagnostic criteria for hypercholesterolemia set in the "Chinese Guidelines on Prevention and Treatment of Dyslipidemia in Adults", i.e., LDL-C $\geq 4.14 \mathrm{mmol} / \mathrm{L}$ [22], 9 out of 15 subjects had hypercholesterolemia.

\section{$L D L-R$ sequencing results}

DNA sequencing of exons showed a $G$ to A substitution at nucleotide 986 in exon 7 resulting in the change of codon 308 from cysteine to tyrosine in the proband and 8 other family members and relatives (Table 3 ). A representative sequencing histogram identifying the mutation and the pedigree chart created based on the DNA sequencing results are shown in Fig. 1.

\section{Scores and FH diagnosis under the DLCN criteria}

The total score under the DLCN criteria for each member is presented in Table 4. All 9 individuals with the C308Y mutation had definite FH while the other members that did not have the mutation had unlikely FH.

\section{Discussion}

In the past 2 decades about 50 cases of the C308Y mutation have been reported [19, 23-31]. Of these, the vast majority are identified in Chinese living in Taiwan province, Hong Kong and Southeast Asia [19, 23-28, 30, 31]. Using the polymerase chain reaction-single strand conformation polymorphism method, Zhu et al. discovered 
Table 2 Demographics and clinical characteristics of all subjects

\begin{tabular}{|c|c|c|c|c|c|c|c|c|}
\hline Subject No & Relationship with the proband & Gender & Age (Years) & BMl & Smoking (Years) & TX & $\mathrm{ATT}(\mathrm{mm}) \mathrm{L}, \mathrm{R}$ & $\mathrm{BP}(\mathrm{mmHg})$ \\
\hline$\|-9$ & Proband & M & 30 's-40's & 24.6 & $>20$ & Yes & 13,13 & $150 / 60$ \\
\hline $1-3$ & Father & M & 60 's-70's & 24.2 & $>30$ & No & - & $150 / 98$ \\
\hline $1-4$ & Mother & $\mathrm{F}$ & 60 's-70's & 19.9 & - & No & - & $130 / 80$ \\
\hline|| $\mid-2$ & Son & M & $10^{\prime} s-20$ 's & 14.5 & - & No & - & $92 / 50$ \\
\hline$\|-6$ & Sister 1 & $\mathrm{~F}$ & 40 's-50's & 17.5 & - & No & - & $140 / 80$ \\
\hline$\|-7$ & Sister 2 & $\mathrm{~F}$ & 40 's-50's & 26.0 & - & No & 7,7 & $130 / 90$ \\
\hline$\|-8$ & Sister 3 & $\mathrm{~F}$ & 30 's-40's & 18.6 & - & Yes & 9,9 & $122 / 80$ \\
\hline$\|-10$ & Brother & M & 20 's-30's & 25.3 & - & Yes & 9,9 & $122 / 88$ \\
\hline$\|-11$ & Sister 4 & F & 30 's-40's & 28.4 & - & No & - & $140 / 90$ \\
\hline$\|-1$ & Cousin 1 & F & 50 's-60's & 23.4 & - & No & - & $140 / 95$ \\
\hline$\|-2$ & Cousin 2 & $F$ & 50 's-60's & 19.5 & - & No & - & $150 / 90$ \\
\hline$\|-3$ & Cousin 3 & $\mathrm{~F}$ & 40 's-50's & 20.4 & $>20$ & Yes & 9,10 & $130 / 90$ \\
\hline$\|-4$ & Cousin 4 & M & 40 's-50's & 20.8 & $>20$ & No & - & $160 / 100$ \\
\hline$\|-5$ & Cousin 5 & M & 40 's-50's & 16.4 & - & No & - & $110 / 70$ \\
\hline|| $\mid-1$ & Nephew & M & 20 's-30's & 18.6 & - & No & - & $140 / 70$ \\
\hline
\end{tabular}

Only 5 members had Achilles tendon thickness measured while the rest declined the measurement

$B M I$ body mass index, $T X$ tendon xanthoma, $A T T$ Achilles tendon thickness, $L$ left, $R$ right, $B P$ blood pressure

a case of C308Y in mainland China [19]. In this sole case, however, neither the clinical data nor the examinations of other family members were recorded. In the present study, we employed physical examinations, lipid profiling, DNA sequencing and the DLCN criteria to investigate a proband and his 14 family members and relatives, and found: 1) 9 out of 15 study subjects carried the C308Y mutation in $L D L-R ; 2)$ apart from the index patient and his father, all other members with the
C308Y variant did not have suggestive CHD manifestations; and 3) under the DLCN criteria, all 9 mutants had definite $\mathrm{FH}$.

The C308Y mutation has been reported most often in isolated individuals, and descriptions of the C308Y mutation in multiple family members are rare. Mak et al. discovered the $\mathrm{C} 308 \mathrm{Y}$ variant in several first-degree family members in Hong Kong, i.e., a father and his 3 children, but the phenotypic characteristics of the children

Table 3 Blood lipid profiling and mutation results of all subjects

\begin{tabular}{|c|c|c|c|c|c|c|}
\hline Subject No & Mutation & TG levels (mmol/L) & TC levels (mmol/L) & LDL-C levels (mmol/L) & HDL-C levels (mmol/L) & $\overline{\mathrm{HCL}}$ \\
\hline II-9 & Yes & 2.80 & 9.96 & 7.44 & 1.4 & Yes \\
\hline $1-3$ & Yes & 1.07 & 8.69 & 6.56 & 2.1 & Yes \\
\hline $1-4$ & No & 2.17 & 4.86 & 2.69 & 1.3 & No \\
\hline|| $\mid-2$ & Yes & 0.90 & 8.05 & 6.19 & 1.5 & Yes \\
\hline$\|-6$ & No & 2.52 & 5.05 & 2.74 & 1.3 & No \\
\hline$\|-7$ & Yes & 2.98 & 10.96 & 8.27 & 1.5 & Yes \\
\hline$\|-8$ & Yes & 0.66 & 7.45 & 5.39 & 1.8 & Yes \\
\hline$\|-10$ & Yes & 1.62 & 10.14 & 7.89 & 1.6 & Yes \\
\hline$\|-11$ & No & 1.70 & 6.43 & 3.25 & 2.5 & No \\
\hline$\|-1$ & Yes & 2.24 & 11.20 & 7.60 & 2.7 & Yes \\
\hline$\|-2$ & No & 2.45 & 5.53 & 2.95 & 1.6 & No \\
\hline$\|-3$ & Yes & 1.13 & 9.08 & 6.83 & 1.8 & Yes \\
\hline$\|-4$ & No & 6.22 & 8.06 & 3.37 & 2.2 & No \\
\hline$\|-5$ & Yes & 0.82 & 9.96 & 6.73 & 2.9 & Yes \\
\hline|| $\mid-1$ & No & 0.57 & 4.08 & 2.15 & 1.7 & No \\
\hline
\end{tabular}

TG triglyceride, TC total cholesterol, LDL-C low density lipoprotein-cholesterol, HDL-C high density lipoprotein-cholesterol, $H C L$ hypercholesterolemia 

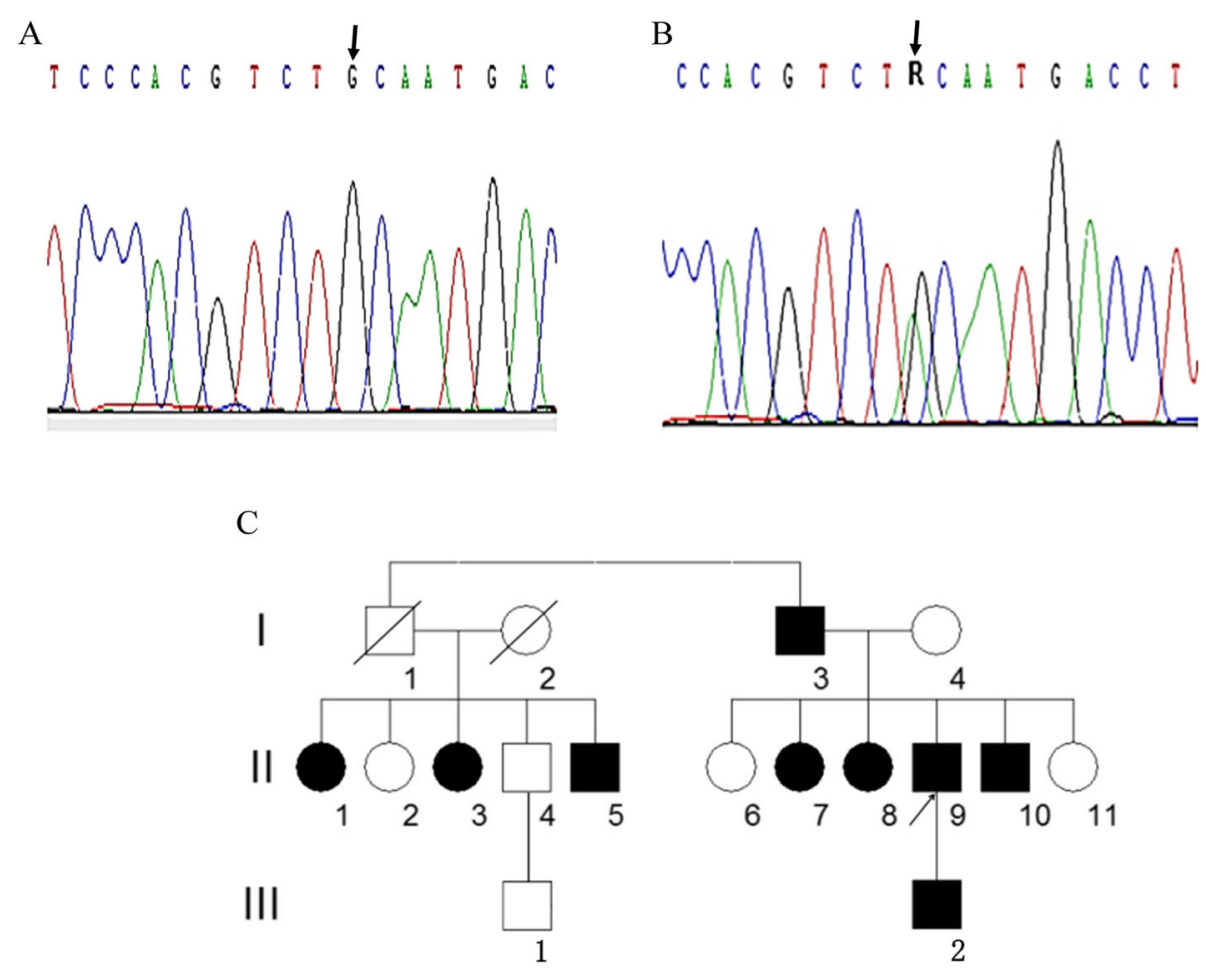

Fig. 1 DNA sequencing results and the pedigree chart. Shown here are the wild-type (panel a) and the C308Y mutation (panel b) DNA sequencing histograms. The nucleotide $\mathrm{G}$ at position 923 of exon 7 in the wildtype (arrow in panel a) was mutated to the nucleotide $\mathrm{A}$ (arrow in panel b) in the heterozygote. According to the DNA sequencing results, a pedigree chart was established (panel c). Unfilled squares are healthy males and filled squares are mutant males; unfilled circles indicate healthy females and filled circles mutant females. A cross line denotes a deceased individual and the arrow indicates proband

Table 4 The scores and diagnosis under the DLCN criteria

\begin{tabular}{lllllllll}
\hline Subject & \multicolumn{7}{l}{ Scores and diagnosis } & \\
\cline { 2 - 6 } & Fh & CH & PE & LDL-C levels & MGT & Total scores & Diagnosis \\
\hline$\|-9$ & 2 & 2 & 6 & 5 & 8 & 23 & Definite FH \\
I-3 & 2 & - & - & 5 & 8 & 15 & Definite FH \\
I-4 & 2 & - & - & - & - & 2 & Unlikely FH \\
$\| I-2$ & 2 & - & - & 3 & 8 & 13 & Definite FH \\
$\|-6$ & 2 & - & - & - & - & 2 & Unlikely FH \\
$\|-7$ & 2 & - & - & 5 & 8 & 15 & Definite FH \\
$\|-8$ & 2 & - & 6 & 3 & 8 & 19 & Definite FH \\
$\|-10$ & 2 & - & 6 & 5 & 8 & 21 & Definite FH \\
$\|-11$ & 2 & - & - & - & - & 2 & Unlikely FH \\
$\|-1$ & 2 & - & - & 5 & 8 & 15 & Definite FH \\
$\|-2$ & 2 & - & - & - & - & 2 & Unlikely FH \\
$\|-3$ & 2 & - & 6 & 5 & 8 & 21 & Definite FH \\
$\|-4$ & 2 & - & - & - & - & 2 & Unlikely FH \\
$\|-5$ & 2 & - & - & 5 & 8 & 15 & Definite FH \\
$\|$ II-1 & 2 & - & - & - & - & 2 & Unlikely FH \\
\hline
\end{tabular}

Fh family history, $C H$ clinical history, $P E$ physical examination, $L D L-C$ low density lipoprotein-cholesterol, $M G T$ molecular genetic testing, $F H$ familial hypercholesterolemia were not provided [23]. A 12-year old girl in Taiwan, who had a dramatically increased concentration of plasma cholesterol $(16.61 \mathrm{mmol} / \mathrm{L})$ and the presence of skin and tendon xanthomas, was identified to be a C308Y mutant [25]. When her family members were consented for molecular genetic testing, the results showed that both of her parents and 3 of her siblings carried the same mutation. In the present study, we genetically analyzed the proband and his 14 family members and relatives, and found 9 individuals carried the $\mathrm{C} 308 \mathrm{Y}$ mutation.

The C308Y mutation results in 70\% loss of LDL-R activity [25], leading to substantially impaired LDL-C clearance and thereby hypercholesterolemia, which is demonstrated in this study and previous reports as well [19, 23-31]. As pharmacological treatment can effectively lower the concentrations of LDL-C to reduce the risk of early onset CHD [6], all subjects harboring the C308Y mutation should therefore take lipid-lowering pharmacologic agents. In this study, lipid-lowering medications were prescribed to all 9 individuals with definite $\mathrm{FH}$.

There have been over $1700 L D L-R$ variants identified thus far, therefore, discovery of specific fingerprints of $L D L-R$ mutations in a region or a population would be helpful for 
focused cascade screening. The C308Y variant has been revealed to cluster in Taiwan and Hong Kong where the origin of most residents are from Southern China including Guangdong, Hainan and Fu Jian provinces [19, 23-28, 30, 31]; and in the present study we discovered the C308Y mutation in multiple family members in Southern China, leading us to speculate that the C308Y might be a common variant in the population of Southern China origin. This hypothesis however, remains to be validated by screening for the C308Y mutation in a large population and, if confirmed, then a tailored molecular testing of C308Y in this target population might be advisable.

The disease database ClinVar contains the assessment results of the C308Y variant' pathogenicity (https://www.ncbi. nlm.nih.gov/clinvar/36809953/). According to the evaluation against the American College of Medical Genetics and Genomics (ACMG) guidelines [32], ClinVar classified 3 different pathogenic roles of C308Y mutation, i.e., likely benign, likely pathogenic and pathogenic. These discordant interpretations in pathogenicity indicate that the C308 variant may have different penetrance in different ethnic groups and that environmental factors may affect the pathogenicity of the C308Y variant. The disagreeing pathogenicity documented in ClinVar could also arise from flaw data collected and analyzed by the database, as the ACMG guidelines point out that disease databases may collect variants that are incorrectly classified for analysis as many studies do not describe detailed information on how patients were ascertained [32].

In 2018, a consensus on FH screening, diagnosis and treatment was published in China, which advocates cascade screening if a patient is diagnosed with $\mathrm{FH}$ [33]. According to the consensus, cascade screening should include family history, clinical history, physical examination, blood LDL-C measurement and genetic testing [33]. Despite this recommendation, in China cascade screening is hindered mainly by low awareness of FH among patients and physicians as well [34]. With respect to genetic testing, several barriers to the test remain to be overcome, which include a limited number of facilities capable of genetic analysis, patients' personal fear of genetic diagnosis and the cost of the test that is not covered by the China National Public Health Insurance [34-36].

It has been shown that individuals with the C308Y mutation have hypercholesterolemia but the occurrence of $\mathrm{CHD}$ in these patients is not well documented [15, 20-28]. In the present study, apart from the proband and his father, all other individuals with $\mathrm{FH}$ did not have clinical manifestations suggestive of $\mathrm{CHD}$, indicating that CHD development is multifactorial.

\section{Conclusions}

The C308Y mutation was discovered in multiple family members and relatives for the first time in mainland
China. Cascade screening is key for the confirmatory diagnosis of $\mathrm{FH}$ cases with the $\mathrm{C} 308 \mathrm{Y}$ mutation. Our hypothesis that the $\mathrm{C} 308 \mathrm{Y}$ is a common variant in the population of Southern China origin warrants further validation by screening for the C308Y mutation in a large population.

\section{Abbreviations \\ ACMG: American College of Medical Genetics and Genomics; CHD: Coronary heart disease; DLCN: Dutch Lipid Clinic Network; FH: Familial hypercholesterolemia; LDL-C: Low density lipoprotein-cholesterol; LDL-R: Low density lipoprotein receptor; LOVD: Leiden Open Source Variation Database}

\section{Acknowledgements}

The authors would like to thank the staff at the Shanghai Human Genome Center for technical assistance in DNA sequencing, and the staff at our Clinical Laboratory Department for help in biochemical testing.

\section{Authors' contributions}

WJ, BW, LP, HQ, DY, XZ, and YD collected and analyzed the data; WJ wrote the manuscript; QZ analyzed the data, wrote and critically revised the manuscript; LL designed the study; LL and MJK supervised the study, and critically revised the manuscript. All authors approved the final version for submission for publication.

\section{Funding}

This work was supported by the Medical and Health Research Project of Hainan Province, China (grant \#: 1421320.24A1005). The funding agency had no role in the design of the study, collection, analysis, and interpretation of data or in writing the manuscript.

Availability of data and materials

All data will be available upon request made to the corresponding author.

Ethics approval and consent to participate

This study was approved by the Research Review Committee of the Third People's Hospital of Hainan Province. Written informed consent to participating in the study was obtained from all subjects.

Consent for publication

All participants were made aware of the possibility of publication of this study by signing the consent form.

\section{Competing interests}

The authors declare that they have no competing interests.

\section{Author details}

${ }^{1}$ Shanghai Human Genome Center, Shanghai, China. ${ }^{2}$ Division of Cardiology, Keenan Research Center for Biomedical Science, St. Michael's Hospital, University of Toronto, Toronto, Ontario, Canada. ${ }^{3}$ Department of Cardiology, the Third People's Hospital of Hainan Province, 1154 Jiefang Road, Sanya 572000, Hainan Province, China

Received: 19 May 2019 Accepted: 9 October 2019

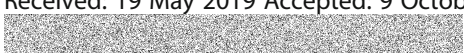

\section{References}

1. Watts GF, Gidding S, Wierzbicki AS, et al. Integrated guidance on the care of familial hypercholesterolemia from the international FH Foundation. J Clin Lipidol. 2014:8:148-72.

2. Soutar AK, Naoumova RP. Mechanisms of disease: genetic causes of familial hypercholesterolemia. Nat Clin Pract Cardiovasc Med. 2007;4:214-25.

3. De Castro-Orós I, Pocoví M, Civeira F. The genetic basis of familial hypercholesterolemia: inheritance, linkage, and mutations. Appl Clin Genet. 2010;3:53-64.

4. Austin MA, Hutter CM, Zimmern RL, Humphries SE. Genetic causes of monogenic heterozygous familial hypercholesterolemia: a HuGE prevalence review. Am J Epidemiol. 2004;160:407-20. 
5. Akioyamen LE, Genest J, Shan SD, et al. Estimating the prevalence of heterozygous familial hypercholesterolaemia: a systematic review and metaanalysis. BMJ Open. 2017;7:e016461.

6. Versmissen J, Oosterveer DM, Yazdanpanah $\mathrm{M}$, et al. Efficacy of statins in familial hypercholesterolaemia: a long term cohort study. BMJ. 2008, 337:a2423.

7. Südhof TC, Goldstein JL, Brown MS, Russell DW. The LDL receptor gene: a mosaic of exons shared with different proteins. Science. 1985;228:815-22.

8. Usifo E, Leigh SE, Whittall RA, et al. Low-density lipoprotein receptor gene familial hypercholesterolemia variant database: update and pathological assessment. Ann Hum Genet. 2012;76:387-401.

9. Vuorio AF, Aalto-Setälä K, Koivisto UM, et al. Familial hypercholesterolaemia in Finland: common, rare and mild mutations of the LDL receptor and their clinical consequences. Ann Med. 2001;33:410-21.

10. Fouchier SW, Defesche JC, Umans-Eckenhausen MA, Kastelein JJ. The molecular basis of familial hypercholesterolemia in the Netherlands. Hum Genet. 2001:109:602-15.

11. Abifadel $M$, Rabès JP, Jambart $S$, et al. The molecular basis of familial hypercholesterolemia in Lebanon: spectrum of LDLR mutations and role of PCSK9 as a modifier gene. Hum Mutat. 2009;30:E682-91.

12. Gudnason V, Sigurdsson G, Nissen H, Humphries SE. Common founder mutation in the LDL receptor gene causing familial hypercholesterolaemia in the Icelandic population. Hum Mutat. 1997;10:36.

13. Dedoussis GV, Schmidt H, Genschel J. LDL-receptor mutations in Europe. Hum Mutat. 2004:24:443-59.

14. Jiang $L$, Sun LY, Dai YF, Yang SW, Zhang F, Wang LY. The distribution and characteristics of LDL receptor mutations in China: a systematic review. SCi Rep. 2015;5:17272.

15. Sturm AC, Knowles JW, Gidding SS, et al. Clinical genetic testing for familial hypercholesterolemia: JACC scientific expert panel. J Am Coll Cardiol. 2018;72:662-80

16. Harada-Shiba M, Arai H, Ishigaki Y, et al. Guidelines for diagnosis and treatment of familial hypercholesterolemia 2017. J Atheroscler Thromb. 2018:25:751-70

17. Nordestgaard BG, Chapman MJ, Humphries SE, et al. Familial hypercholesterolaemia is underdiagnosed and undertreated in the general population: guidance for clinicians to prevent coronary heart disease: consensus statement of the European atherosclerosis society. Eur Heart J. 2013;34:3478-90.

18. Migliara G, Baccolini V, Rosso A, et al. Familial hypercholesterolemia: a systematic review of guidelines on genetic testing and patient management. Front Public Health. 2017;5:252

19. Zhu DM, Chen ZJ, Chen BS, et al. A study on point mutations of lipoprotein receptor gene in patients with hypercholestemia. Chinese Circ J. 2001;16:180-2.

20. Wang B, Zhang Q, Lin L, et al. Association of Achilles tendon thickness and LDL-cholesterol levels in patients with hypercholesterolemia. Lipids Health Dis. 2018;17:131

21. Harada-Shiba M, Arai H, Oikawa S, et al. Guidelines for the management of familial hypercholesterolemia. J Atheroscler Thromb. 2012;19:1043-60.

22. Joint committee for developing Chinese guidelines on prevention and treatment of dyslipidemia in adults. Chinese guidelines on prevention and treatment of dyslipidemia in adults. Chinese J Cardiol. 2007:35:390-419.

23. Mak YT, Zhang J, Chan YS, et al. Possible common mutations in the low density lipoprotein receptor gene in Chinese. Hum. Mutat. 1998; Suppl.1:S310-3.

24. Mak YT, Pang CP, Tomlinson B, et al. Mutations in the low-density lipoprotein receptor gene in Chinese familial hypercholesterolemia patients. Arterioscler Thromb Vasc Biol. 1998;18:1600-5.

25. Chang JH, Pan JP, Tai DY, et al. Identification and characterization of LDL receptor gene mutations in hyperlipidemic Chinese. J Lipid Res. 2003:44:1850-8

26. Khoo KL, van Acker P, Defesche JC, et al. Low-density lipoprotein receptor gene mutations in a southeast Asian population with familial hypercholesterolemia. Clin Genet. 2000;58:98-105.

27. Charng MJ, Chiou KR, Chang HM, Cheng HM, Ye ZX, Lin SJ. Identification and characterization of novel low-density lipoprotein receptor mutations of familial hypercholesterolaemia patients in Taiwan. Eur J Clin Investig. 2006:36:866-74.

28. Zakharova FM, Damgaard D, Mandelshtam MY, et al. Familial hypercholesterolemia in St-Petersburg: the known and novel mutations found in the low density lipoprotein receptor gene in Russia. BMC Med Genet. 2005;6:6.

29. Punzalan FE, Sy RG, Santos RS, et al. Low density lipoprotein--receptor $(\mathrm{LDL}-\mathrm{R})$ gene mutations among Filipinos with familial hypercholesterolemia. J Atheroscler Thromb. 2005;12:276-83.

30. Chiou KR, Charng MJ. Common mutations of familial hypercholesterolemia patients in Taiwan: characteristics and implications of migrations from Southeast China. Gene. 2012;498:100-6.

31. Chiou KR, Charng MJ. Detection of common sequence variations of familial hypercholesterolemia in Taiwan using DNA mass spectrometry. J Clin Lipidol. 2017:11:386-93.

32. Richards S, Aziz N, Bale S, et al. Standards and guidelines for the interpretation of sequence variants: a joint consensus recommendation of the American College of Medical Genetics and Genomics and the Association for Molecular Pathology. Genet Med. 2015;17:405-24.

33. Chinese Society of Cardiology. A consensus on the screening, diagnosis and treatment of familial hypercholesterolemia. Chinese J Cardiol. 2018;46:99-103.

34. Chen $P$, Chen $X$, Zhang S. Current status of familial hypercholesterolemia in China: a need for patient FH registry systems. Front Physiol. 2019;10:280.

35. Cao YX, Wu NQ, Sun D, et al. Application of expanded genetic analysis in the diagnosis of familial hypercholesterolemia in patients with very earlyonset coronary artery disease. J Transl Med. 2018;16:345.

36. Shi Z, Yuan B, Zhao D, Taylor AW, Lin J, Watts GF. Familial hypercholesterolemia in China: prevalence and evidence of underdetection and undertreatment in a community population. Int J Cardiol. 2014;174:834-6.

\section{Publisher's Note}

Springer Nature remains neutral with regard to jurisdictional claims in published maps and institutional affiliations.
Ready to submit your research? Choose BMC and benefit from:

- fast, convenient online submission

- thorough peer review by experienced researchers in your field

- rapid publication on acceptance

- support for research data, including large and complex data types

- gold Open Access which fosters wider collaboration and increased citations

- maximum visibility for your research: over $100 \mathrm{M}$ website views per year

At $\mathrm{BMC}$, research is always in progress.

Learn more biomedcentral.com/submissions 